\title{
Study of Natural Dyes and Pineapple Leaf Fibres Growing Locations within Plant Stems on Dyeing Intensity.
}

\author{
Amin Rejo ${ }^{1, *}$, Rizky Tirta Adhiguna ${ }^{1}$, and Debora Geovanni Rajagukguk ${ }^{2}$ \\ ${ }^{1}$ Department of Agricultural Technology, Universitas Sriwijaya, Indonesia \\ ${ }^{2}$ Graduate Student, Department of Agricultural Technology, Universitas Sriwijaya, Indonesia
}

\begin{abstract}
The physical properties of fibres produced from pineapple leaves can vary due to the differences in growing locations within a stem and are influenced by leaf growth age. Pineapple leaf fibres require quality increase, particularly in dyeing. The utilizing of natural dyes ingredients from suji (Dracaena angustifolia) leaves extract, turmeric (Curcuma domestica val) and sappan (Caesalpinia sappan [L.]) wood have friendly impact on the environment. Various types of natural dyes and leaf fibres growing location within the stems of pineapple plants and the color intensity are carefully examined in this study. The diversity of natural dyes used in dyeing influenced the fibres color intensity of pineapple leaves. Pinneaple leaf fibers growing loccation within pineapple stems impacted fibre color lightness intensity, the axis $\mathrm{a}^{*}$ and $\mathrm{b}^{*}$ colors. The utilization of pineapple leaf fibers from the base of plant stem is more suitable to be used as textile raw material due to its higher lightness level.
\end{abstract}

\section{Introduction}

Almost all regions of Indonesia are pineapple-producing regions (Ananas comosus [L.]) because they are supported by tropical climatic conditions. Indonesia is the third largest pineapple producer after Philippines and Thailand with a contribution of around $23 \%$ in Southeast Asian region [1]. Generally, farmers in Indonesia utilize agricultural waste in the form of leaves from pineapple production to be used as fertilizer and animal feed, while fibre parts which has a high enough value in terms of its function and economic value can be taken from pineapple leaves [2].

Cellulose content in pineapple leaf fibres is quite high compared to other natural fibre sources which reach $85 \%$ and only lower than hemp cellulose content by $91 \%$. The higher the cellulose content, the stronger the yield fibre is and not easily damaged. Young pineapple leaves can produce short and weak fibres, while too old pineapple leaves produce short, coarse and brittle fibres. Pineapple leaf extraction is carried out at the age of plants 1 to 1.5 years [3]. Pineapple leaf fibres contributed with excellent mechanical properties

*Corresponding author: aminrejo@unsri.ac.id 
compared to other natural fibers hence make it as an effective raw material in textiles manufacturing by binary or multi blending [4]. Pineapple leaf fibres is white in color, smooth and glossy as silk [5].

Natural dyes utilizing development as textile dyes in recent years has increased. This is related to environmental sustainability issues and a ban on the use of synthetic dyes in countries such as Netherlands and Germany which require the use of environmentally friendly textile dyes materials and do not approve the use of synthetic dyes [6]. Natural dyeing agents or vegetable dyes are dyeing agents derived from plants [7]. Natural dyes have advantages and disadvantages. A good dyes on textile material will become unattractive to consumers if the textile material is faded in color [3].

Natural fibres quality requires an increase in the quality of raw materials, particularly in dyeing. The quality of textile products can be reviewed from two aspects, namely physical and chemical aspects. Physical aspects can be seen from tensile strength testing, while for chemical aspects through absorption testing [8]. Natural dyeing ingredients are very easy to find in Indonesia. Natural dyeing such as the colors provided by extract of sappan wood (Caesalpinia sappan [L.]), turmeric (Curcuma domestica val) and suji leaves (Dracaena angustifolia).

The physical properties of fibres produced from pineapple leaves can vary due to the differences in growing locations in the stem and are influenced by leaf growth age. Further natural dyeing is used to determine the physical properties of the different pineapple leaves on the stem after being given natural dyes, because not all natural fibres can absorb dyes properly. This study was conducted to determine the effect of natural dyes types and the growing location of leaf fibres within plant stem on color intensity.

\section{Materials and Methods}

Research started by collecting pineapple leaves from cultivation garden in Ogan Ilir, South Sumatra. Pineapple leaves from the base (P) with a height of 0-100 mm, middle (T) with a height of 100.01-200 mm, the top (A) with a height of 200.01-300 mm within plant stem. Fibres collecting step from pineapple leaves and natural substances producing using the procedure as reported by Wijana et al 2016 [3]. Dyeing proccess of pineapple leaf fibres using the procedure reported by Anzani et al 2016 [9] which had used the colors provided by the extract of suji leaves (S), turmeric (K) and sappan wood (C). Measurement of physical properties of pineapple leaf fibres dyeing using a procedure reported by Billmeyer and Saltzman 1981 [10]. The data were analyzed using analysis of variance processed with differences considered significant when $\mathrm{P}<0.05$. Separation means were carried out by least significant difference (LSD).

\section{Results and Discussions}

\subsection{Effect of Natural Dyes Types on Color Intensity}

The results showed that natural dyes type had an effect on the color intensity values of $L^{*}, a^{*}$ and $b^{*}$ in pineapple leaf fibres. The highest average $L$ value of pineapple leaf fibres was $59.73(\mathrm{~S})$, while the lowest was $41.40(\mathrm{C})$. This finding explained that the pineapple leaf fibres which was colored by suji leaf extract had higher brightness compare to the other two natural dyes.

Further, the research showed that axis a* color intensity of pineapple leaf fibres was influenced by natural dyes types. The average value of the highest axis a* of pineapple leaf 
fibres was $12.57(\mathrm{~K})$ and the lowest was $6.63(\mathrm{~S})$. This showed that turmeric dye type produces darkest red color while the colors of suji leaf and sappan wood produces color inclined to green.

The axis $b^{*}$ color intensity of pineapple leaf fibres was also influenced by natural dyes types. The highest average value of axis $b^{*}$ of pineapple leaf fibres was $22.67(\mathrm{~K})$ while the lowest was $4.80(\mathrm{C})$. The axis $\mathrm{b}^{*}$ value shows yellow color intensity if it is positive and blue color intensity if it is negative. Turmeric contains curcumoid compounds carrying yellow natural dyes so as influence the color intensity of pineapple leaf fibres [3].

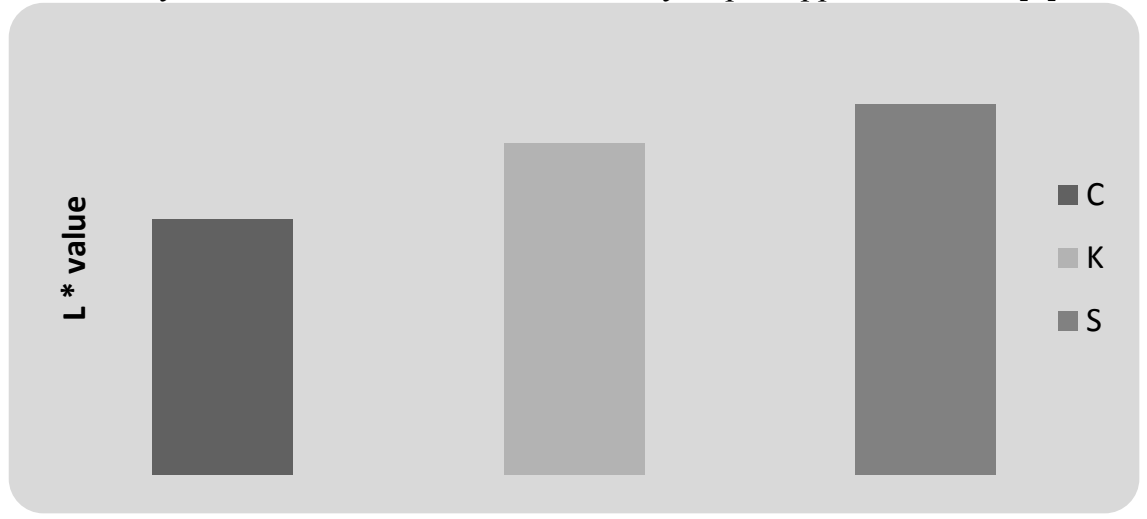

Fig. 1.The $L^{*}$ value of pineapple leaf fibres with natural dyes.

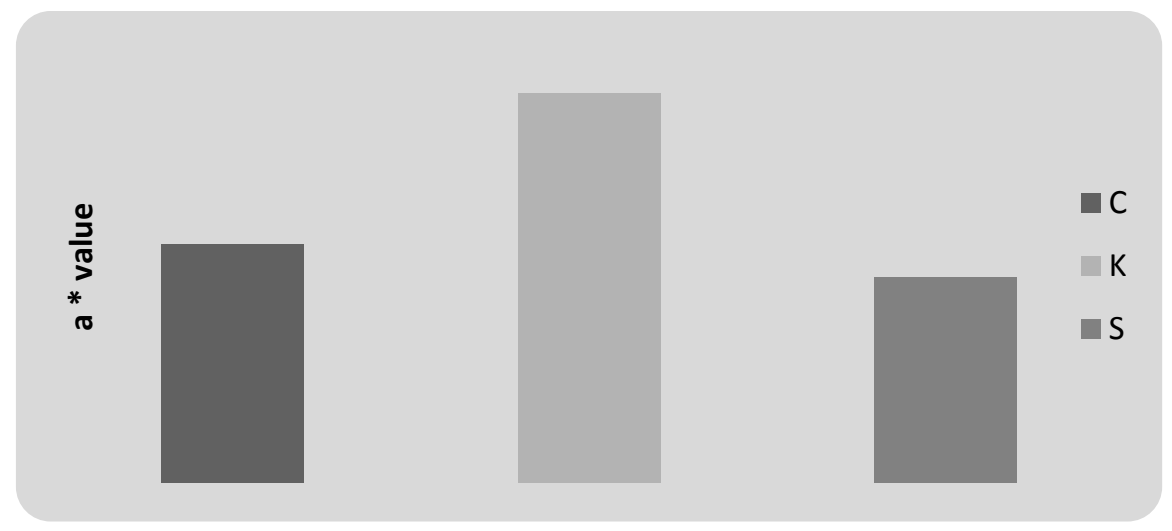

Fig. 2.The Axis a* value of pineapple leaf fibres with natural dyes.

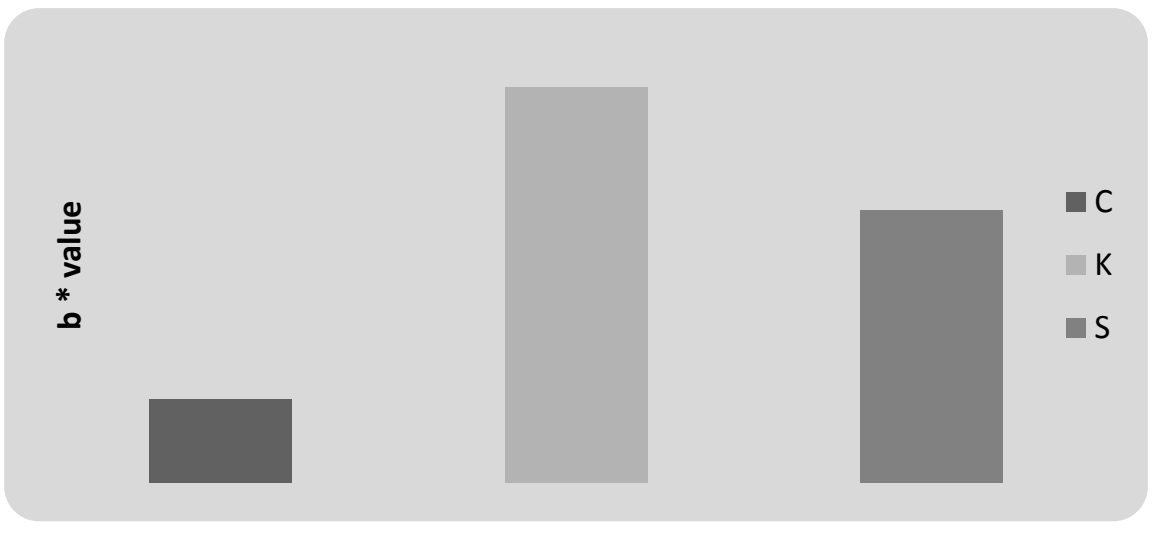


Fig. 3.The Axis $b^{*}$ value of pineapple leaf fibres with natural dyes.

\subsection{Effect of Fiber Growing Location on Color Intensity}

The $\mathrm{L}^{*}$ color intensity value is represented as lighter or darker (lightness-darkness) in the range 0-100 (white to black). The results showed that leaf fibres growing location in the base and top of within the plant stem impacted fibre brightness intensity ( $\left.\mathrm{L}^{*}\right)$. The highest average $\mathrm{L}^{*}$ color intensity value was $53.17(\mathrm{P})$ while the lowest was $49.00(\mathrm{~A})$. It indicated that fibres from leaves at the base had higher level of brightness than fibres from leaves at the middle and top part of the plant stem. The brightness level of leaf fibres from the base part is able to reflect higher percentage of light better than leaf fibres from the middle and top part of the plant stem [11].

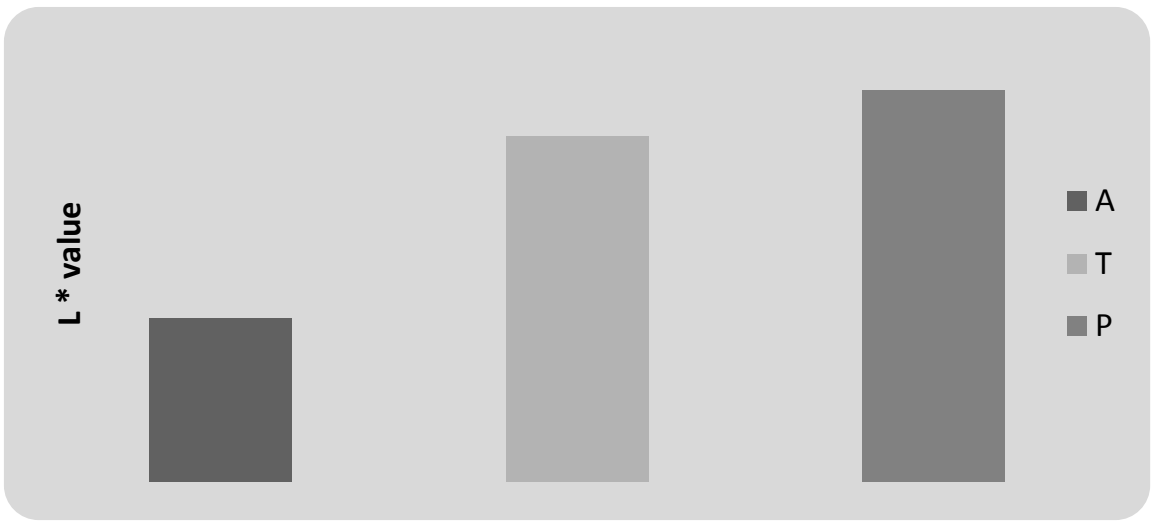

Fig. 4. The $L^{*}$ value of pineapple leaf fibres from different locations within plant stemwith natural dyes.

The axis $\mathrm{a}^{*}$ value is represented as redish (redness) if it is positive in the range 0 to 80 and greenish if it is negative in the range 0 to -80 , while the axis $b *$ value is yellowish (yellowness) if it is positive in the range 0 to 70 and bluish if negative in the range of 0 to 70 [12]. The highest average score for axis a* color intensity was $10.10(\mathrm{~T})$ and the lowest was $7.87(\mathrm{P})$, while the highest average for axis $\mathrm{b}^{*}$ color intensity was $15.33(\mathrm{~T})$ and the lowest was $12.53(\mathrm{P})$. The difference in leaf fibres growing location within the plant stems affected the axis $\mathrm{a}^{*}$ and $\mathrm{b}^{*}$ color values.

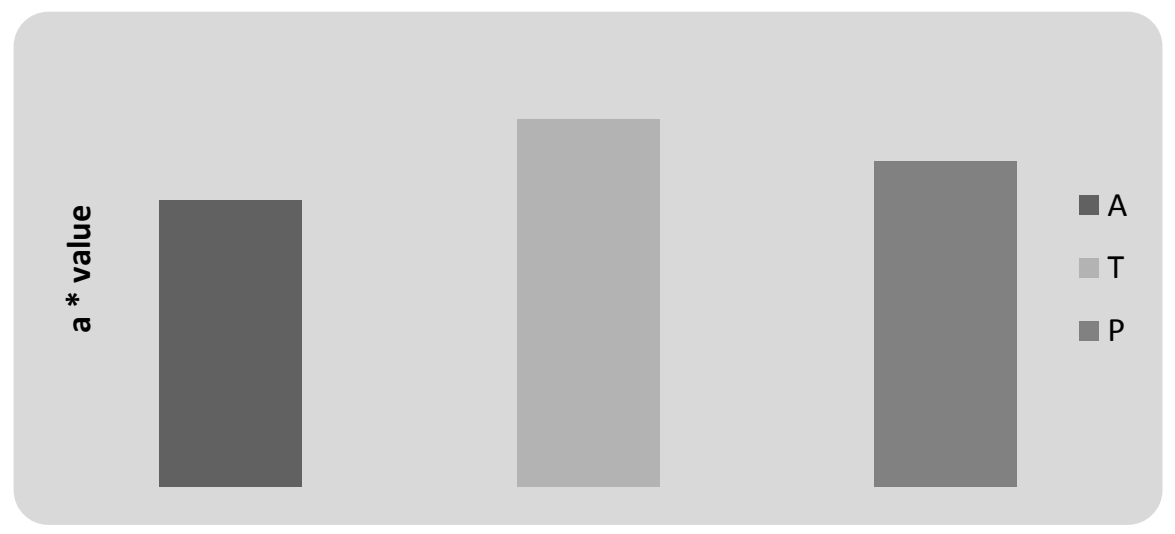


Fig. 5.The axis a* value of pineapple leaf fibres from different locations within plant stemwith natural dyes.

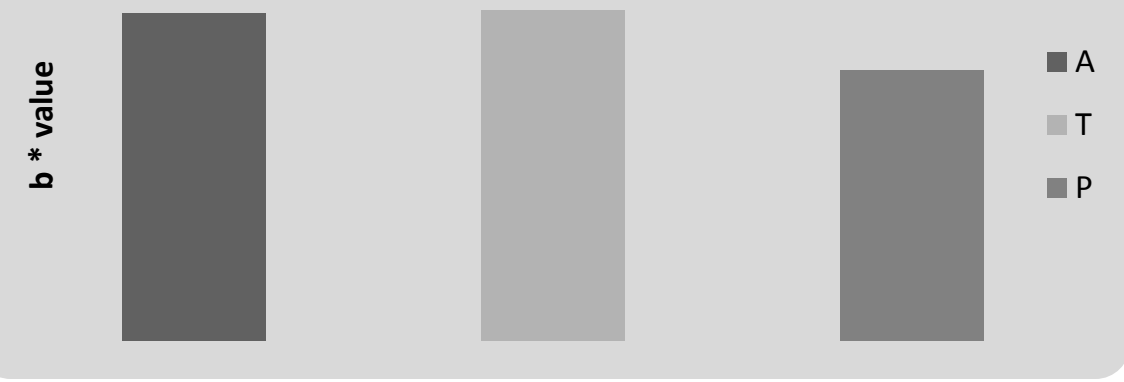

Fig. 6.The axis $b *$ value of pineapple leaf fibres from different locations within plant stemwith natural dyes.

\section{Conclusion}

Pineapple production waste in the form of pineapple leaves can be used as a source of natural fibres and textile raw materials. Various types of natural dyes can be applied to pineapple leaf fibres such as the dyes ingredients produced by suji leaf extract, turmeric and sappan wood. The diversity of natural dyes used in dyeing impacted fibres color intensity of pineapple leaves. Growing location of pineapple leaf fibres within pineapple stems affected fibre color lightness intensity, the axis $a^{*}$ and $b^{*}$ colors. The utilization of pineapple leaf fibres from the base of the plant stem is more appropriate to be used as textile raw material because it has higher lightness level.

\section{References}

1. R. R. B. Lubis, A. Daryanto, M. Tambunan, H. P. S. Rachman. J. Agroekonomi 32 (2014).

2. Wijoyo, Sugiyanto, C. Pramono. J. Mekanika 9, 2 (2011)

3. S. Wijana, I. A. Dewi, E. D. P. Setyowati. J. Industria. JTMA 5, 1 (2016).

4. Y. Yusof, S. A. Yahya, A. Adam. J. ARPN 11, 1 (2016).

5. R. Kannojiya, K. Gaurav, R. Ranjan, N. K. Tiyer, K. M. Pandey, J. ERD 7, 4 (2013).

6. Kasmudjo, P. S. Panji. J. MAPEKI, 12 (2010)

7. P. Hidayat. J. Teknoin 13, 2 (2008)

8. D. A. Wedyatmo, A. S. Nugroho. J. Politeknosains 12, 2 (2013)

9. S. D. Anzani, Wignyanto, M. H. Pulungan, S. R. Lutfi. J. Industria. JTMA 5, 3 (2016)

10. Billmeyer. Saltzman. Principles of colour technology (Wiley Interscience, New York, 1981)

11. Jayanudin. J. Rekayasa Proses 3, 1 (2009)

12. M. Hosseini, M. Montazer, R. Damerchely. J. JEFF 8, 3 (2013) 